\title{
Observations on the Anatomy of Ash-wood with Reference to Water-conductivity.
}

\author{
BY \\ M. G. HOLMES, B.Sc. \\ With seven Figures in the Text.
}

$A \mathrm{~N}$ investigation into the anatomy of Ash-wood has been carried out on A the lines of that described for Hazel-wood in a previous paper. ${ }^{1}$ Attention was directed chiefly to the proportion of the water-conducting elements present in the wood. The results are presented graphically, and are intended to make possible a comparison between different parts of the same shoot as regards this character, as well as between shoots which differ in size and vigour.

\section{MATERIAL。}

As in the case of the Hazel, the Ash-wood here investigated was all wood of the first year. Three of the specimens, $A_{3}, A_{4}$, and $A_{6}$, were typical stool shoots, long, thick, and unbranched, with long internodes and the scars of large leaves; they were cut on March 10, I9I8, from separate Ash stools which had had one season's growth after coppicing. Specimen A 8 was cut on May 18,1918 , from an Ash stool of four years' growth, being the upper part of one of the shoots, bearing several laterals of the previous season; three of these were chosen for comparison with the firstyear stool shoots. They are much shorter than the latter, and lack some of the vigour characteristic of the juvenile form. At the season when A 8 was cut, the buds had opened and the leaves were beginning to expand; the external appearance of the shoot is shown in Fig. I.

In the Ash the opposite leaves of a pair are often not placed exactly level; sometimes in the stool shoots they are several centimetres apart. In these circumstances the position of the node was taken for convenience of comparison as the middle transverse plane between the upper limits of the two leaf scars, and the internodes were measured accordingly. The lengths of the whole shoots and of their internodes are compared in Fig. 2. The

1 Holmes, M. G. : A Study in the Anatomy of Hazel-wood with Reference to Conductivity of Water. Ann. of Bot., vol. xxxii, 1918.

[Annals of Botany, Vol. XXXIII. No. CXXX. April, 1919.] 
large axillary buds are placed well above the insertion of the leaf, and often below the large bud there is a much smaller supernumerary one. In the Ash shoot the terminal bud is generally present, but frequently it does not develop farther, and in the next season the strongest shoots grow out from

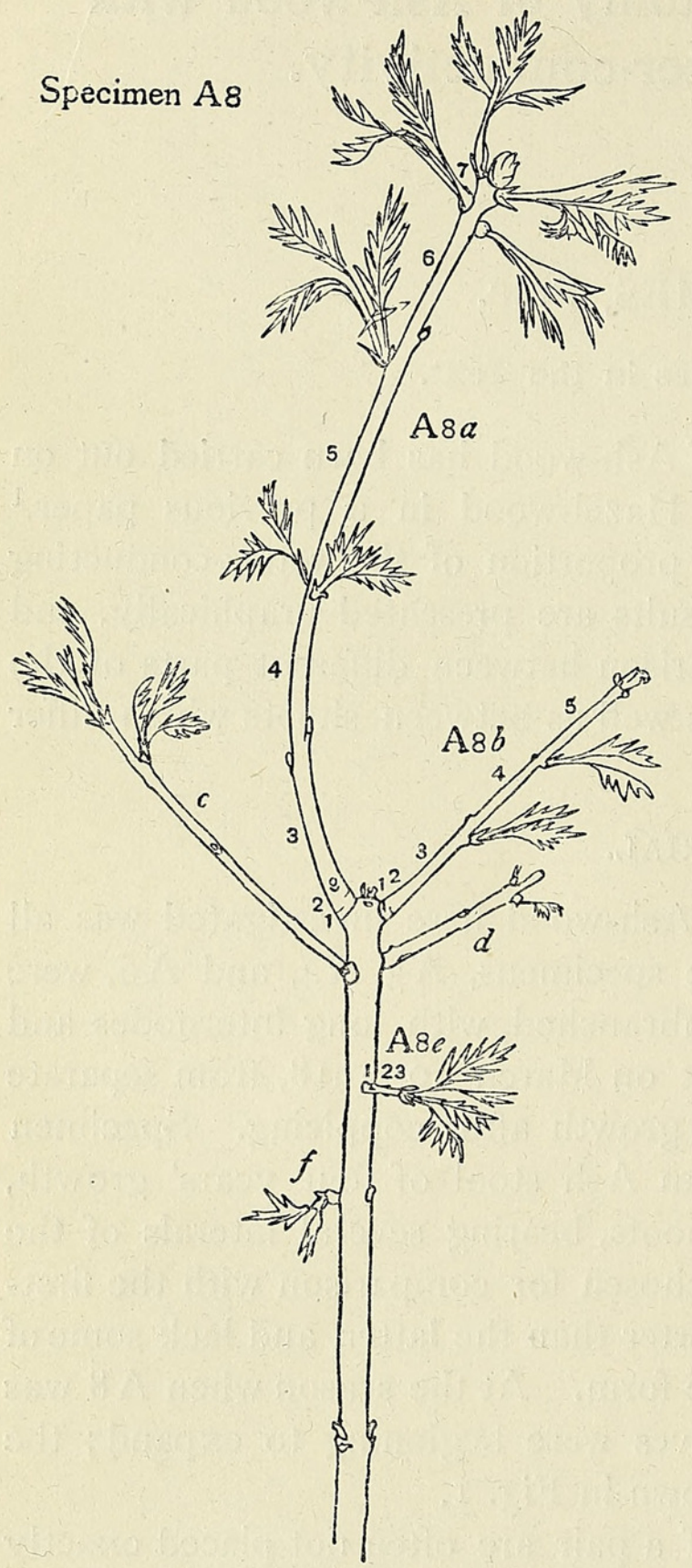

Fig. I. The numbers refer to the internodes, reckoned from the base of each shoot respectively. The statistics of shoots A $8 a$, A $8 b$, A $8 e$, are given in Fig. 7 . the lateral buds near the apex. The apices of specimens $\mathrm{A}_{3}, \mathrm{~A}_{4}$, and A 6 are compared in Fig. 3 ; it was found that the apical buds of $\mathrm{A}_{3}$ and $\mathrm{A}_{4}$, the shorter shoots, were strong, while that of A 6 , the longer shoot, was weaker. In specimen A 8 is seen the result of the abortion of the terminal bud. That formed in 1916 failed to develop, and in I9I7 six shoots grew out from lateral buds, getting less vigorous from the top downwards; a similar condition is repeated in the development of the buds of A $8 a$, the strongest of these shoots, at the opening of the season of 1918. In the Ash a number of the shoots which do develop are not permanent; such weak shoots as A $8 e$ are likely to be suppressed very soon. In A $8 b$ the apex was dying back by the failure of the apical and also the lateral buds at the end.

\section{Anatomy.}

In the young and vigorous stool shoots there is a wide pith, especially in the middle part of the shoot. At the base, the wood cylinder is particularly wide between the cambium and the pith, and it decreases in width towards the apex relatively more than does either the pith or the cortex. There is a complete cylinder of wood in the terminal internode of each of these shoots, widest in $A_{3}$, internode $I_{I}$, in the sense indicated above, and very narrow in A6, internode 15 . In A 8 the cambial activity had been resumed at the time that the specimen was cut, so that some new wood of the 1918 season was present; but this new spring wood was not taken into 
account in the investigation, and the figures from which the graphs were drawn refer to the wood developed in the first season only, so that these graphs can be compared fairly with those given for $\mathrm{A}_{3}, \mathrm{~A}_{4}$, and $\mathrm{A} 6$, and also with those for the Hazel shoots, ${ }^{1} \mathrm{H} 7$ to $\mathrm{H}$ io. The wood cylinder for the first year is completely closed in all the sections cut from A8, and is particularly wide between the cambium and the pith in internode 6 at the end of $\mathrm{A} 8 \mathrm{a}$.

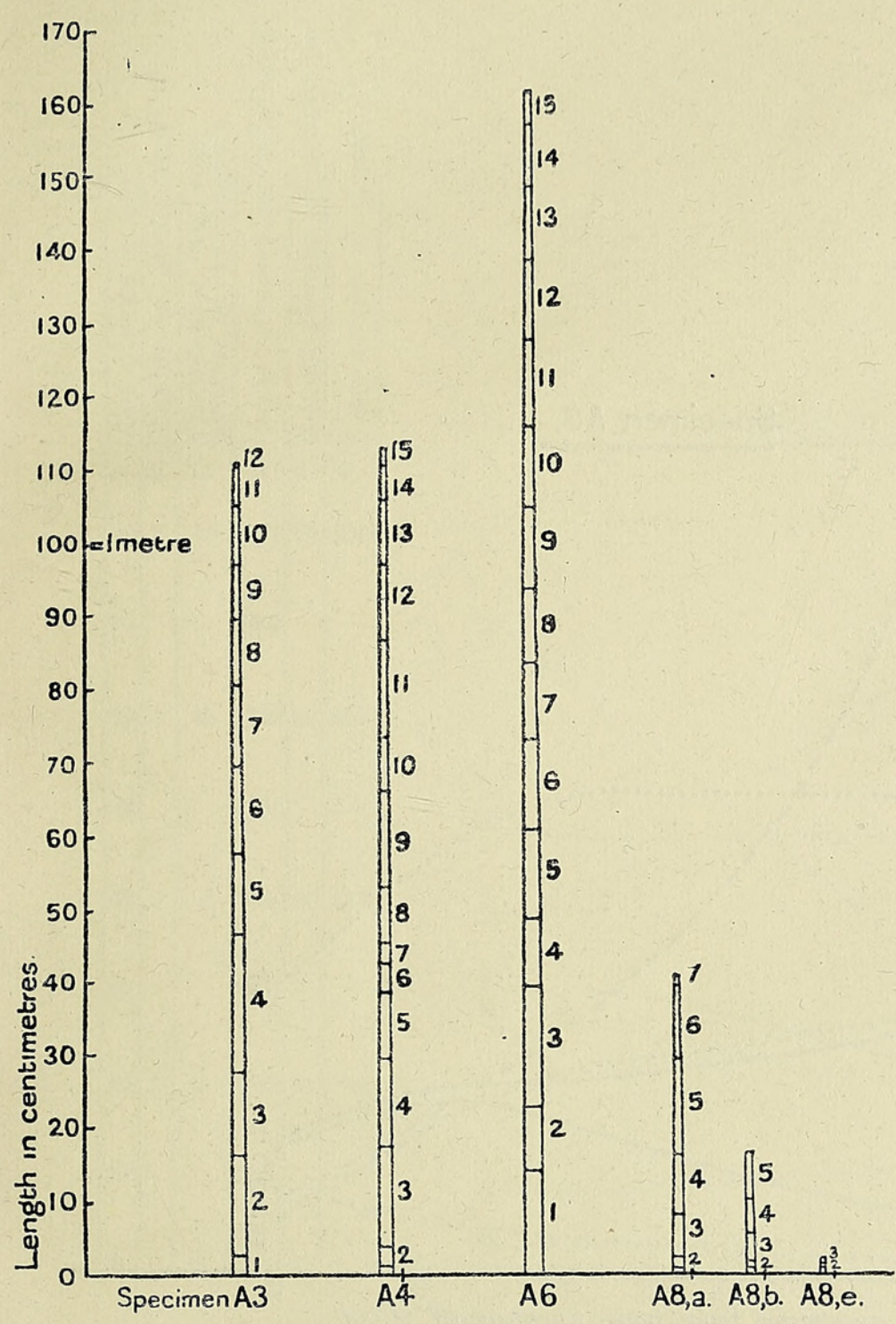

Fig. 2. The numbers refer to the internodes on each shoot respectively.

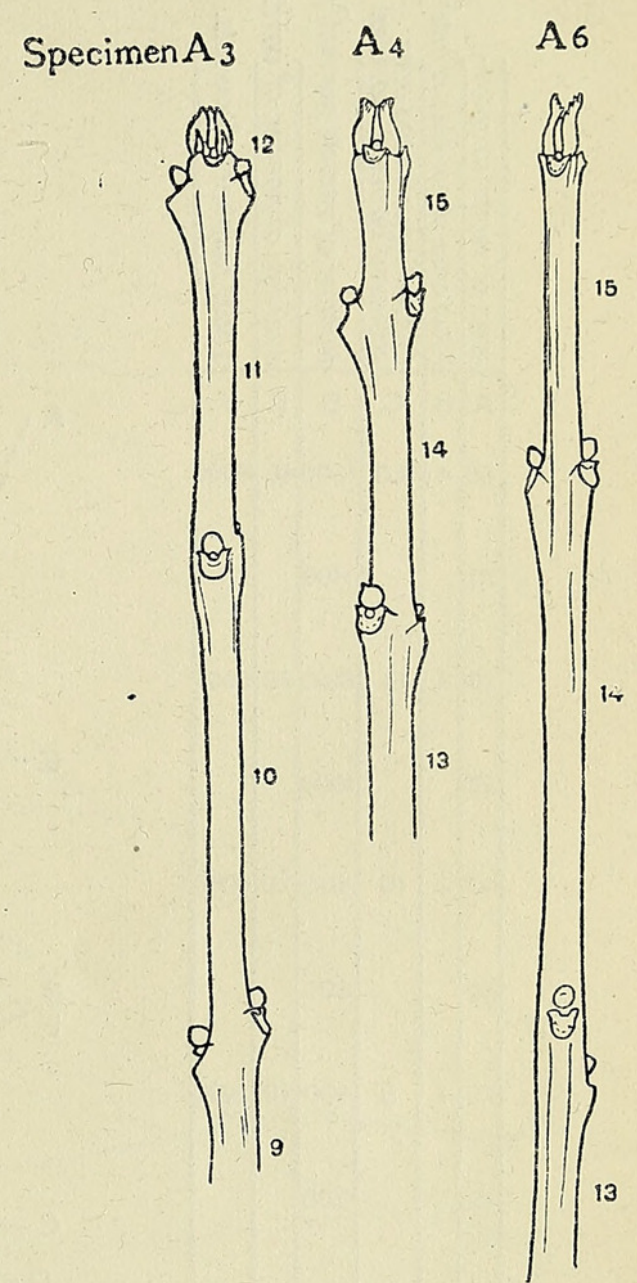

Fig. 3. The numbers refer to internodes, reckoned from the base of the shoot.

The water-conducting elements in Ash-wood are all vessels; there are no tracheides. The vessels are scattered among wood fibres, and are especially associated with wood parenchyma in vertical strands, the latter being most abundant near the autumnal limit of the cylinder.

The wood is crossed by numerous medullary rays, one or two cells wide, and often many cells deep. The vessels are mostly round or elliptical in transverse section, and have numerous bordered pits in their walls; they

1 Holmes, M. G. : loc. cit. 
are easily distinguished by their size and shape from the wood fibres, and by their walls, which are thicker, pitted, and more completely lignified than those of the latter. The small vessels near the cambium are very thickwalled, with a quite circular lumen. Spirally thickened vessels occur in the protoxylem next to the pith. In longitudinal section the vessels are seen to consist of short segments communicating by round holes, chiefly in radial oblique walls; the segments of the wide vessels may be four or five times

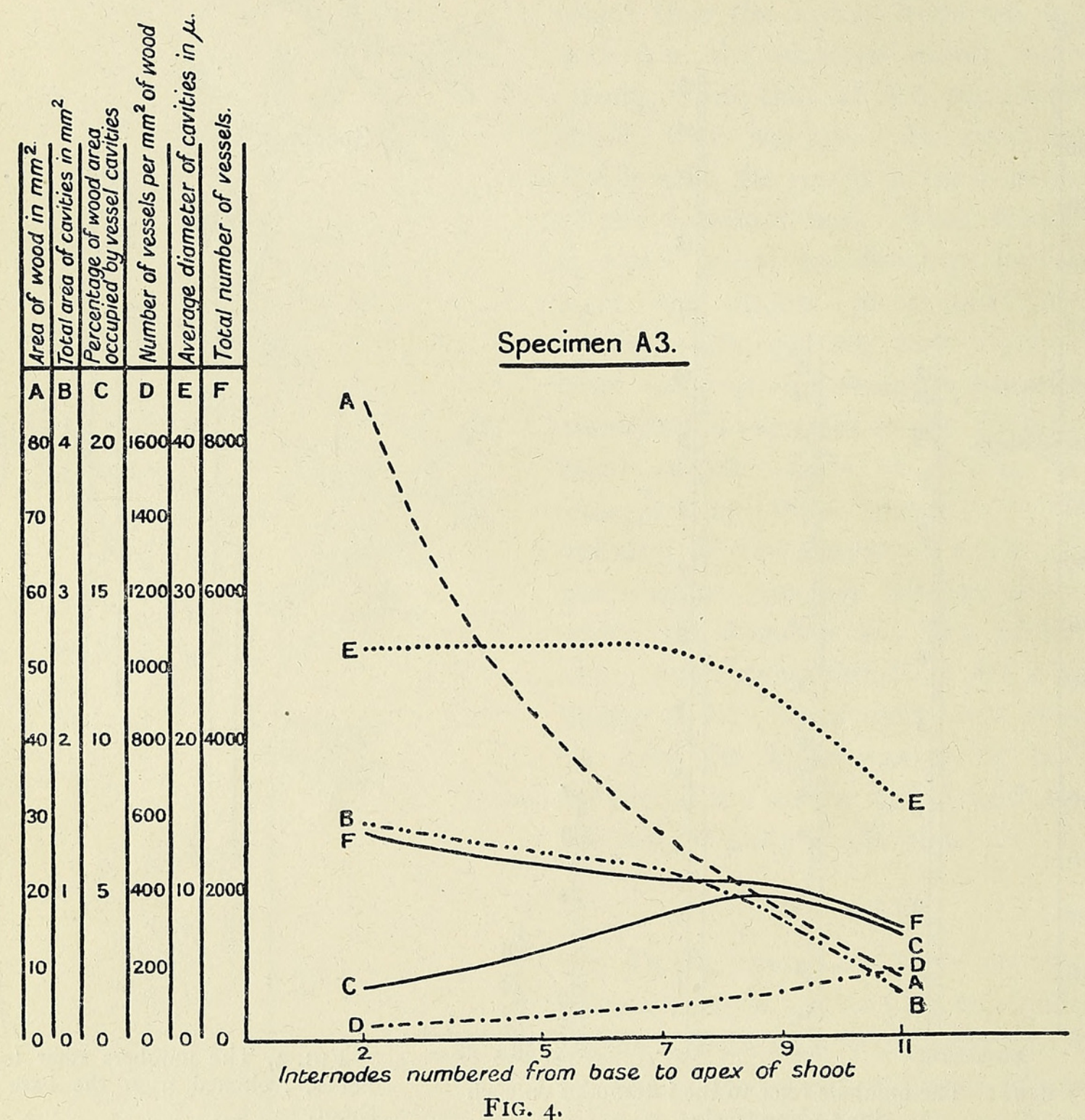

as long as they are wide, but are often shorter. The wood is richest in vessels immediately round the pith, especially in the four groups of primary xylem corresponding with the opposite and decussate phyllotaxy. In all except the smallest sections, where the widest vessels occur in these primary groups, there are wider vessels in the region of the wood just outside this part, and they get smaller again towards the periphery, and more scattered. Apart from the primary bundles, the distribution of the vessels is very uniform in most of the sections, especially at the lower levels. 


\section{METHOD.}

The data as to the size, proportion, and distribution of the water-conducting elements were obtained in substantially the same manner as that described for the Hazel. ${ }^{1}$ In many of the smaller sections it was found practicable to obtain the total number of the vessels by actual counting in the whole or a large part of the section.

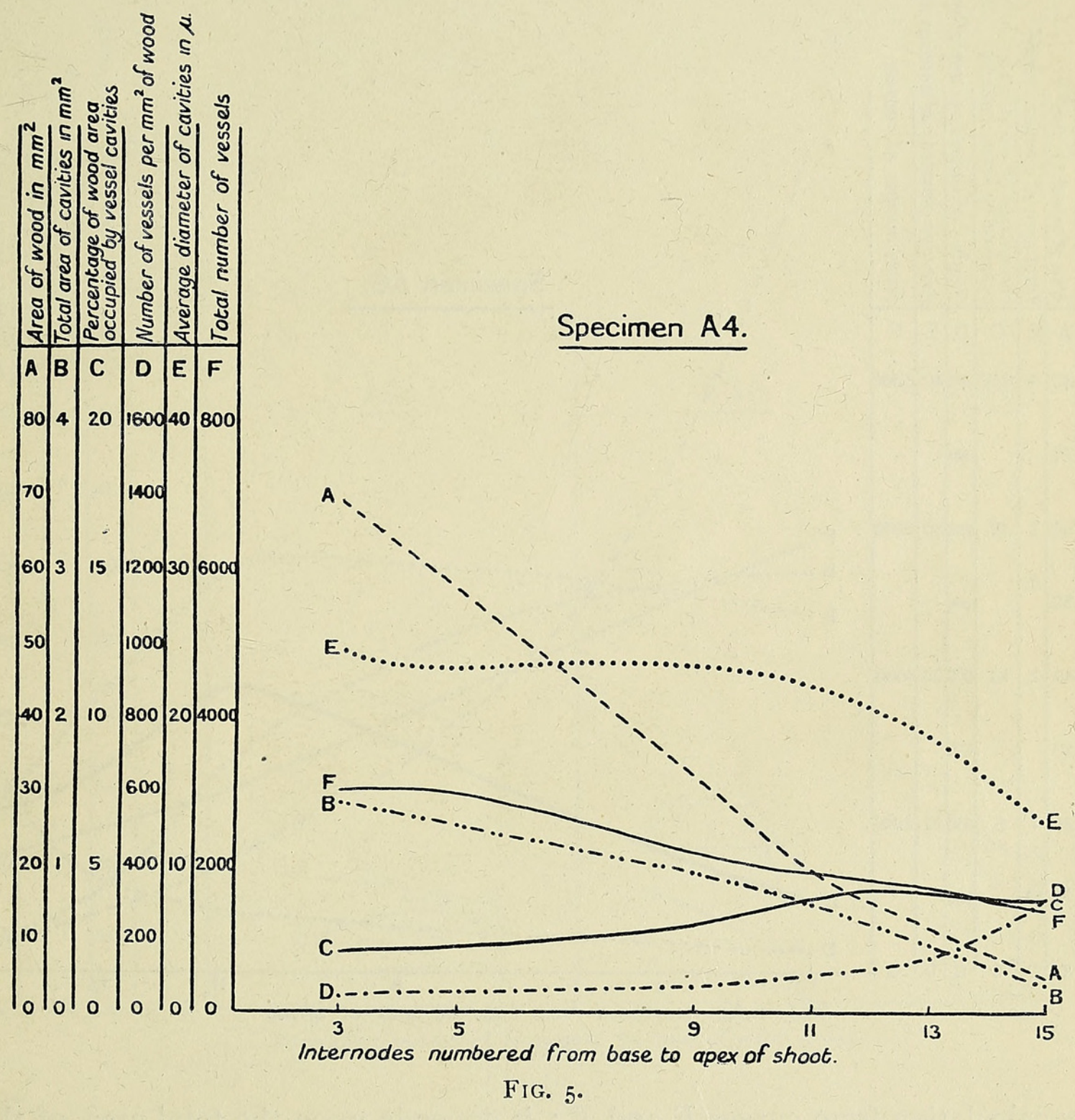

RESULTS.

The figures are presented in graphical form, a set of six curves being given for each shoot. These lines are lettered to correspond with those given for the Hazel shoots, and the vertical scales are the same. It has been found convenient, however, to double the horizontal scale, in which an equal interval was taken for each internode regardless of its length; for in the

\footnotetext{
1 Holmes, M. G. : loc. cit.
} 
stool shoots of the Ash the internodes are longer and fewer than in the Hazel stool shoots, and also each bears two leaves.

The total or absolute conductivity for water is represented, for purposes of comparison in this inquiry, by the area in square millimetres of all the vessels in each transverse section of the wood, taken at the middle points of the selected internodes. This is shown in curve $B$, and is obtained

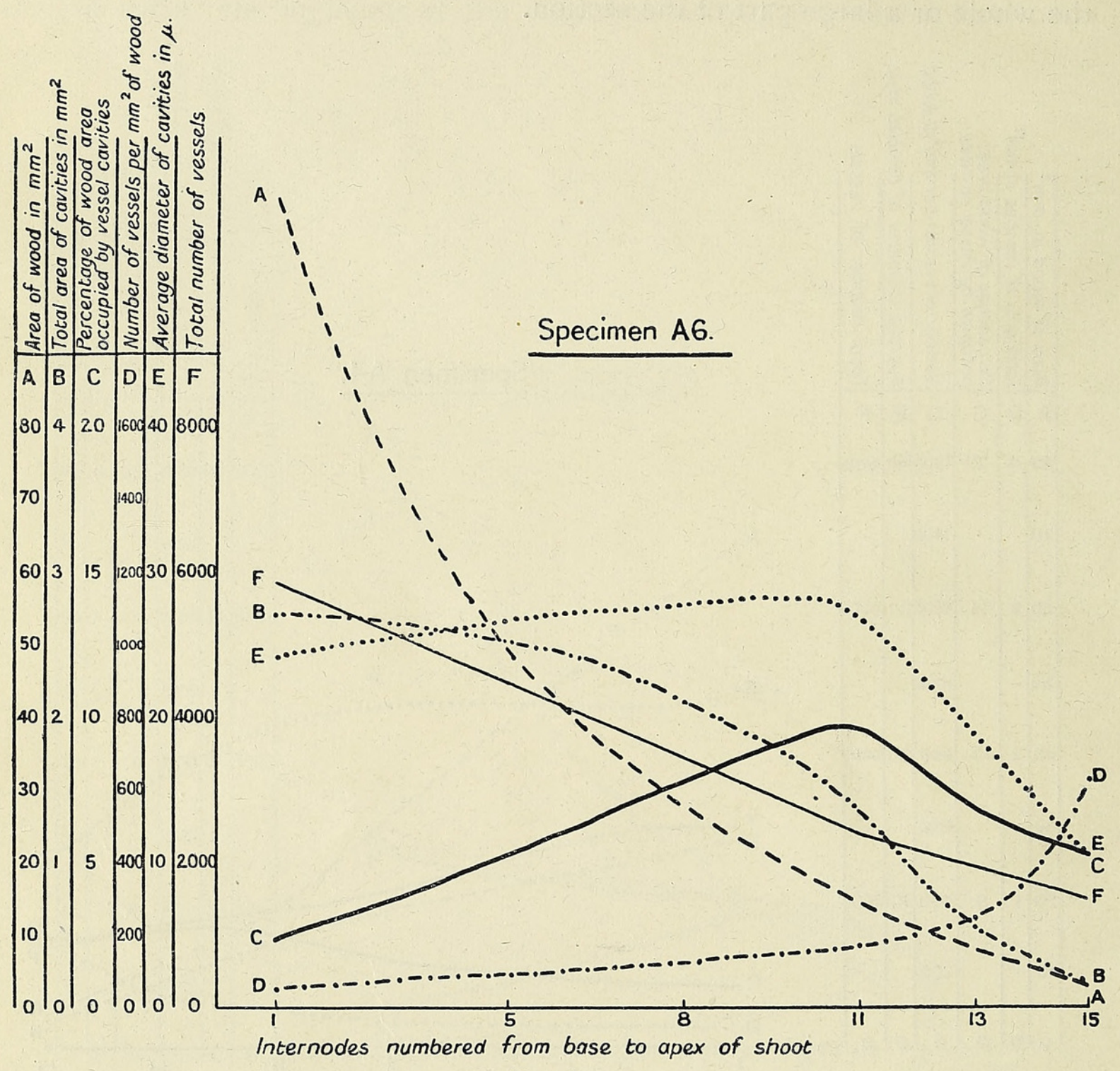

FIG. 6.

by calculation from curves $\mathrm{F}$ and $\mathrm{E}$; it depends upon the total area of the wood, given in curve $\mathrm{A}$, as well as upon its specific quality.

Curve $A$, giving the variation in area of the wood along each shoot, shows in general a very regular descent, rather steeper at the base; this is especially the case in the larger shoots, in which considerable support is necessary.

Curve $F$ gives the total number of vessels present in the transverse section at the different levels in each shoot. It shows a fairly steady decline from base to apex; in A $8 b$ the decline is particularly steep. 
Curve $E$ gives the average diameter of the vessel cavities in the transverse section of the wood, measured in $\mu$. The figure obtained for each section depends of course on the proportion of wide to narrow vessels, as well as on their actual widths. The curve keeps fairly level or may rise slightly from the base upwards for the greater part of the length of the shoot, and then falls again towards the apex. Only the fall is seen in the very small shoot $\mathrm{A} 8 e$. Curve $\mathrm{E}$ reaches its highest point in

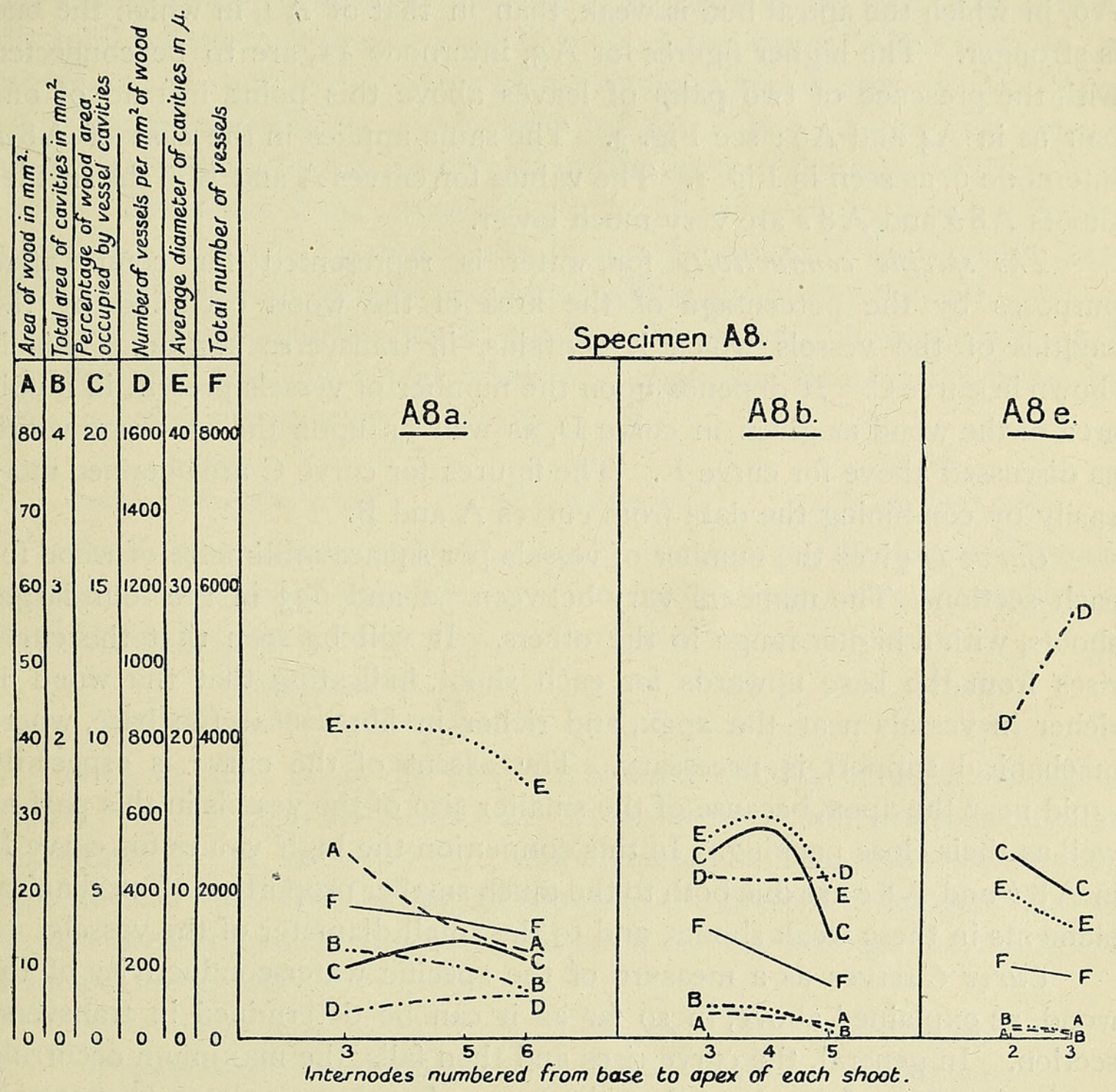

FIG. 7 .

A 6 at internode Io (the highest calculated figure being $27 \cdot 85 \mu$ at $\mathrm{A} 6,8$ ), but this of course is only an average value. In all sections narrow as well as wide vessels are present, but on the whole they are narrower in the smaller sections, and the rapid decline of the curve towards the apex is due to the absence of the larger vessels. The highest diameters recorded in each shoot for a single vessel were as follows :

$\begin{array}{ccccccc}\text { Shcot No. } & \text { A } 6 & \text { A }_{3} & \text { A }_{4} & \text { A } 8 a & \text { A } 8 b & \text { A } 8 e \\ \text { Diameter of widest vessels in } \mu . & 80 & 76 & 72 & 46 & 32 & 28\end{array}$


The vessels formed in the beginning of the second annual ring in A 8 are much wider than any present in the first ring, as is usual.

Curve $B$ shows the total area of all the vessel cavities in each section, and represents the absolute water-conductivity. It is obtained by combining the data from curves $\mathrm{F}$ and $\mathrm{E}$, and shows in general a corresponding decline from the base to the apex of the shoot. It is to be noticed that both the curves $A$ and $B$ reach a lower point in the terminal internode of A6, in which the apical bud is weak, than in that of $\mathrm{A}_{4}$, in which the bud is stronger. The higher figures for $\mathrm{A}_{3}$, internode $\mathrm{I} \mathrm{I}$, are to be connected with the presence of two pairs of leaves above this point, instead of one pair as in $\mathrm{A}_{4}$ and A6; see Fig. 3. The same applies in the case of A $8 a$, internode 6 , as seen in Fig. $I$. The values for curves $A$ and $B$ in the smaller shoots $\mathrm{A} 8 \mathrm{~b}$ and $\mathrm{A} 8 \mathrm{e} e$ are very much lower.

The specific conductivity for water is represented for comparative purposes by the percentage of the area of the wood occupied by the cavities of the vessels which it contains, in transverse section. This is shown in curve $C$. It depends upon the number of vessels present in a unit area of the wood as given in curve $\mathrm{D}$, as well as upon their average width as discussed above for curve $\mathrm{E}$. The figures for curve $\mathrm{C}$ are obtained most easily by combining the data from curves $A$ and $B$.

Curve $D$ gives the number of vessels per square millimetre of wood for each section. The numbers vary between 32 and 633 in the four larger shoots, with a higher range in the others. It will be seen that the curve rises from the base upwards for each shoot, indicating that the wood is richer in vessels near the apex, and richer in fibres near the base, where mechanical support is necessary. The ascent of the curve is especially rapid near the apex, because of the smaller size of the vessels in this part as well as their close packing. In this connexion the high values for curve $D$ in $\mathrm{A} 8 \mathrm{~b}$ and $\mathrm{A} 8 \mathrm{e}$ are due both to the much smaller proportion of mechanical elements in these weak shoots, and to the small diameter of the vessels.

Curve $C$ serves as a measure of the specific water-conductivity of the wood, as explained above, in so far as it can be determined in transverse section. In general, the curve rises and then falls, the maximum occurring nearer the apex of the shoot than the base. In other words, up to a certain point the increase in the number of vessels, per unit area, makes the wood more efficient for water-conduction, its merely strengthening function being gradually reduced, but when the vessels get very small, the wood becomes less efficient again, their walls occupying a relatively larger area in proportion to their cavities. The rise and fall are shown in a general way by a comparison as a whole of the three curves for A 8 ; the figures are low for A $8 a$, where there is a fairly high proportion of fibres, and fairly low again for $\mathrm{A} 8 e$, where the vessels are very narrow. The sharp drop in curve $C$ for the final internode in $A 8 b$ is interesting in view of the failure on the part 
of the buds at the apex of this shoot to develop. It was observed that this part of the shoot was alive at the resumption of cambial activity in the spring, for the section showed some development of new elements, though very slight as compared with that in the lower internodes. The highest value recorded for curve $C$ was 9.5 per cent. at internode II in A6, while the maximum for $\mathrm{A} 8 \mathrm{~b}$ at internode 4 reached 6.9 per cent. The lowest value was $\mathrm{I} \cdot 68$ per cent. at internode 2 in $\mathrm{A}_{3}$. The percentage of 'conducting area', curve $C$, is lower at the base of $A_{3}$ than at the base of $A_{4}$, while the total 'conducting area', curve $B$, is about the same; this is because the larger area of wood in $\mathrm{A}_{3}$, internode 2 , contains a higher proportion of fibres.

Comparison with the results obtained for Hazel. There is a general resemblance between Ash and Hazel in the figures obtained for their stool shoots. The forms of the curves are similar, showing on the whole a decline in absolute conductivity with a rise in specific conductivity from the base of the shoot towards its apex, the latter falling again near the end.

The actual values for specific conductivity, curve $C$, however, are much lower for Ash than for Hazel, taken as a whole, the limits of variation for the shoots examined being as follows:

Plant.

Ash.

Hazel.

Range of values for curve C

1.68 to 9.5 per cent.

$3 \cdot 2$ I to $20 \cdot 26$ per cent.

This is in agreement with the results obtained by Professor Farmer, ${ }^{1}$ for the two kinds of wood in question, by his experimental method of determining specific conductivity. His figures are quoted below:

$\begin{array}{ccc}\text { Stool Shoots of } & \text { Ash. } & \text { Hazel. } \\ \text { Normal range of specific conductivity } & \text { I } 4 \pm \text { I0 } & 3 \mathrm{I} \pm 9\end{array}$

Thus in both cases the figures obtained for Hazel-wood are about double those obtained for Ash-wood. In order to account anatomically for this difference we may compare the diameters of the water-conducting elements and their distribution, as shown in the present investigation. For the shoots examined the ranges of variation for the average and the actual diameters are as follows:

Stool Shoots of

Rnnge of values for curve $\mathrm{E}$ in $\mu$

Rang of actual diameters in $\mu$
Ash.

27.85 to $10 \cdot 14$ 8 o to 3
Hazel.

$23^{\circ} 27$ to $4 \cdot 9$ 48 to 2

It is evident that, on the whole, the water-conducting elements are wider in Ash than in Hazel, so that the reason for the lower specific conductivity in Ash does not find its explanation in this feature. Turning to the distribution of these elements, the ranges of variation for the shoots examined are as follows :

Stool Shoots of

Range of values for curve $\mathbf{D}$
Ash.

32 to 633
Hazel.

I 5 to 4,000

1 Farmer, J. B. : On the Quantitative Differences in the Water-conductivity of the Wood in Trees and Shrubs, Parts I and II. Proc. Roy. Soc., B., vol. xc, I9I8. 
Thus on the whole Hazel-wood has a greater number of water-conducting elements per square millimetre than Ash-wood, which more than compensates for the smaller diameter of these elements and their greater resistance to the flow of water on this account. The relatively low specific conductivity of Ash-wood must be attributed to its relative poverty in vessels. It is to be understood that these observations apply to wood of the first year only, and that a still greater range of variation might, and probably would, be found for some of the characters-for instance, in those forming the basis of curve E-by examining a larger number of examples; but I am inclined to think that the general range for specific conductivity would not be altered materially, and that the relation between Ash-and Hazel-wood in this respect would remain as indicated above.

\section{SumMary.}

The results obtained from a quantitative investigation of the constitution of Ash-wood in young shoots, with special reference to vessel content, have been discussed, and compared with similar data previously obtained for Hazel-wood. It is shown that on the whole there is a fall in absolute water-conductivity and a rise in specific conductivity from the base of a shoot to its apex, in both kinds of wood examined, and that, in general, the figures for specific conductivity are lower in Ash than in Hazel. In the latter the water-conducting elements are more numerous than in the former, though on the whole they are not so wide.

My thanks are due to Professor Farmer, of the Imperial College, South Kensington, for his suggestion of this work and his help in carrying it out, and to Professor Potter, of Armstrong College, Newcastle-on-Tyne, where part of the work was undertaken. 


\section{$2 \mathrm{BHL}$ Biodiversity Heritage Library}

Holmes, M. G. 1919. "Observations on the anatomy of ash-wood with reference to water-conductivity." Annals of botany 33, 255-264. https://doi.org/10.1093/oxfordjournals.aob.a089720.

View This Item Online: https://www.biodiversitylibrary.org/item/235681

DOI: https://doi.org/10.1093/oxfordjournals.aob.a089720

Permalink: https://www.biodiversitylibrary.org/partpdf/320256

\section{Holding Institution}

Smithsonian Libraries

\section{Sponsored by}

Biodiversity Heritage Library

\section{Copyright \& Reuse}

Copyright Status: Not in copyright. The BHL knows of no copyright restrictions on this item.

This document was created from content at the Biodiversity Heritage Library, the world's largest open access digital library for biodiversity literature and archives. Visit BHL at https://www.biodiversitylibrary.org. 